\title{
CORRIGENDUM
}

\section{Diet of the Antillean manatee (Trichechus manatus manatus) in Belize, Central America - CORRIGENDUM}

\author{
AARIN CONRAD ALLEN, CATHY A. BECK, ROBERT K. BONDE, JAMES A. POWELL \\ AND NICOLE AUIL GOMEZ
}

https://doi.org/10.1017/So025315417000182 Published online by Cambridge University Press, 3 April 2017

Keywords: feeding ecology, dietary habits, microhistological analysis, herbivory, seagrass, corrigendum

The authors would like to address potential misunderstandings in the above publication.

The original abstract for this article read as follows:

Belize contains important habitat for Antillean manatees (Trichechus manatus manatus) and provides refuge for the highest known population density of this subspecies. As these animals face impending threats, knowledge of their dietary habits can be used to interpret resource utilization. The contents of 13 mouth, six digestive tract (stomach, duodenum and colon) and 124 faecal samples were microscopically examined using a modified point technique detection protocol to identify key plant species consumed by manatees at two important aggregation sites in Belize: Southern Lagoon and the Drowned Cayes. Overall, 15 different items were identified in samples from manatees in Belize. Five species of seagrasses (Halodule wrightii, Thalassia testudinum, Ruppia maritima, Syringodium filiforme and Halophila sp.) made up the highest percentage of items. The red mangrove (Rhizophora mangle) was also identified as an important food item. Algae (Ulva sp., Chara sp., Lyngbya sp.) and invertebrates (sponges and diatoms) were also consumed. Variation in the percentage of seagrasses, other vascular plants and algae consumption was analysed as a 4-factor analysis of variance (ANOVA) with main effects and interactions for locality, sex, size classification and season. While sex and season did not influence diet composition, differences for locality and size classification were observed. These results suggest that analysis of diet composition of Antillean manatees may help to determine critical habitat and use of associated food resources which, in turn, can be used to aid conservation efforts in Belize.

It should in fact read:

Belize contains important habitat for Antillean manatees (Trichechus manatus manatus) and provides refuge for the highest known population density of this subspecies. As these animals face impending threats, knowledge of their dietary habits can be used to interpret resource utilization. The contents of 13 mouth, six digestive tract (stomach, duodenum and colon) and 124 faecal samples were microscopically examined using a modified point technique detection protocol to identify key plant species consumed by manatees at two important aggregation sites in Belize: Southern Lagoon and the Drowned Cayes. Overall, 15 different items were identified in samples from manatees in Belize. Five species of seagrasses (Halodule wrightii, Thalassia testudinum, Ruppia maritima, Syringodium filiforme and Halophila sp.) made up the highest percentage of items. The red mangrove (Rhizophora mangle) was also identified as an important food item. Algae (Ulva sp., Chara sp., Lyngbya sp.) and a small amount of invertebrates (including sponges) were also consumed. Variation in the percentage of seagrasses, other vascular plants and algae consumption was analysed as a 4-factor analysis of variance (ANOVA) with main effects and interactions for locality, sex, size classification and season. While sex and season did not influence diet composition, differences for locality and size classification were observed. These results suggest that analysis of diet composition of Antillean manatees may help to determine critical habitat and use of associated food resources which, in turn, can be used to aid conservation efforts in Belize. 
Additionally, the diatoms noted in the examined contents (Table 1, Appendices A, C, E and F) were present in the exoskeleton of invertebrates and identified as diatomaceous earth fragments and calcium carbonate deposits. These items were not considered to be significant food items but ingested incidentally with the invertebrates consumed. Therefore for the purposes of the analyses presented, these fragments were grouped with sponges and unknown invertebrates under the 'Invertebrate' category of these tables.

\section{REFERENCE}

Allen A.C., Beck C.A., Bonde R.K., Powell J.A. and Gomez N.A. (2017) Diet of the Antillean manatee (Trichechus manatus manatus) in Belize, Central America. Journal of the Marine Biological Association of the United Kingdom. Cambridge University Press, pp. 1-10. doi: 10.1017/ Soo25315417000182. 